\title{
Ensinar a filosofar no ensino médio: uma proposta metodológica
}

\author{
Maria Helena Ferreira Goulart*
}

\begin{abstract}
Resumo
Este artigo propõe analisar as dificuldades dos docentes de Filosofia no Ensino Médio em encontrar uma metodologia que desperte o interesse dos alunos pelo ato de filosofar. Apesar de existir um consenso acerca de sua importância nesse nível de ensino, há uma contínua e pertinente indagação sobre o que ensinar e como ensinar. Assim, tem-se por referências Kant e Hegel, na medida em que, procurar-se-á discutir um método de ensino que possa efetivamente contribuir para o bom desempenho do docente da referida disciplina em sala de aula e, consequentemente, despertar o interesse dos alunos pelas grandes questóes da Filosofia, pela tradiçáo filosófica, de maneira a não torná-la apenas o espaço de opiniôes e de repetiçôes de ditos comuns historicamente construídos. Em seguida, dedica-se a repensar a formação inicial do professor desta disciplina. Embora tenham ocorrido mudanças significativas nos cursos de licenciatura que preparam os futuros filósofos professores, o contexto que envolve essa formação é complexo, já que a licenciatura sempre foi vista com desdém pelas academias que priorizam o bacharelado.
\end{abstract}

Palavras-chave: filosofia, metodologia, ensino médio, filosofar.

\section{Teaching philosophy in high school: a proposed methodology}

\section{Abstract}

This article proposes to examine the difficulties experienced by philosophy teachers at high school level in finding a methodology to make students interested in philosophizing. Although there is consensus about its importance at this level of education, a pertinent question remains about what and how to teach. Thus, Kant and Hegel are their references if one wants to discuss a teaching method which will effectively contribute towards effective teaching of this subject in the classroom and consequently make students interested in the fundamental issues of philosophy, the philosophical tradition, so that it is not just a space for opinions and repetitions of historically constructed common sayings. Then the article goes on to rethink the initial formation phase of the philosophy teacher. Despite the significant changes that have occurred in licentiate courses in terms of the preparation of future philosophy teachers, the context in which such formation occurs is complex, since the licentiate has always been disdained by the prevailing university system which prioritizes the preparation of future researchers.

Keywords: philosophy, methodology, high school, philosophizing.

\footnotetext{
* Licenciada em Filosofia pela Universidade Federal de Goiás, Professora de Filosofia no Colégio Zênite em Inhumas, Goiás. E-mail: mghelena18@gmail.com.
} 


\section{Introduçáo}

Não é possível expor em apenas um artigo todos os pontos abertos quando se trata do ensino da filosofia no Ensino Médio. Portanto, pretendese discutir uma metodologia para o ensino desta disciplina a partir dela mesma, ou seja, pensar filosoficamente o que ensinar e como, pois há aspectos específicos que devem ser abordados pela própria filosofia. Conforme afirma Danelon (2010, p. 3), "neste aspecto, acreditamos ser importante pensar o ensino da Filosofia desde um olhar da própria Filosofia. Em outras palavras, pensar filosoficamente o ensino de Filosofia é pensar com a Filosofia o problema do seu ensino".

Neste prisma, entende-se que ensinar filosofia abrange basicamente duas tarefas: o ensino dos conceitos criados pelos filósofos e o do ato de filosofar, que é, segundo Kant, o exercício da razão. Deste modo, é importante compreender que ensinar a história da filosofia não é simplesmente transmitir informaçôes, mas, em contrapartida, despertar para iniciativas problematizantes.

Neste enfoque, há uma urgência e necessidade de repensar não só a questão do método, mas também a formação inicial do professor de filosofia. A licenciatura nos cursos desta disciplina nunca foi benquista pelas academias que sempre priorizaram o bacharelado. $\mathrm{O}$ modelo dos cursos de formação de professor, em muitos casos ainda em vigência, remete à dicotomia teoria e prática. Esta dicotomia se concretiza na falta de compreensão da realidade escolar por parte do futuro professor, que, somente no final de curso começa a preocupar-se com sua atuação na sala de aula.

Razōes ideológicas, ou seja, a tentativa de inibir o pensar crítico, levou a filosofia a um movimento pendular nos currículos. Outro aspecto que demonstra o descaso para com a filosofia é o fato de professores de outras áreas do conhecimento ministrarem aulas desta disciplina para completarem sua carga horária. Ora, assim como é inadmissível um professor habilitado em filosofia ministrar outras disciplinas, porque, evidentemente não possuiria o domínio dos conteúdos específicos de cada uma, na filosofia não poderia ser diferente. No entanto, as instituiçóes de ensino, principalmente as públicas estaduais, outorgam ao professor de qualquer área a administração de aulas de filosofia. Logo, por não deter o conhecimento necessário e suficiente, ele se torna obrigado a fazer o que é intolerável, colocar o aluno para decorar por meio de fichamentos a história da filosofia ou, o que já foi dito, transmitir 
informaçôes vazias de significado. Com esses procedimentos didáticos, é compreensível e aceitável o desinteresse do aluno pela disciplina.

Dessa forma, a filosofia não tem como mostrar a que veio. De acordo com Sílvio Gallo, em entrevista concedida a Juliano Orlandi (2011, p. 1),

se a obrigatoriedade [do ensino da filosofia] é fruto de uma luta que começou na década de 1970 e teve muitos momentos distintos, é também verdade que se a Filosofia náo se consolidar como disciplina na educação média poderá ser retirada novamente, com uma "canetada" qualquer. Se a mobilização e a luta para sua inclusão foram grandes, penso que o trabalho agora é ainda maior, pois temos que garantir que a Filosofia seja ensinada efetivamente e o seja de modo significativo. Se não conseguirmos provar, com um bom trabalho, que a Filosofia é uma contribuição importante para a formação dos jovens brasileiros, ela será retirada. E aí talvez não tenha volta possível...

Ou seja, para que a filosofia ocupe realmente o espaço que lhe é devido e contribua de fato na formação dos jovens, é necessário o comprometimento por parte das escolas públicas e privadas com a contratação de bons professores, com formação específica na área.

\section{Ensinar filosofia ou a filosofar?}

Esta é uma questão comum quando se trata do ensino da filosofia. Kant e Hegel, em sua produção filosófica, retratam esta dupla possibilidade. O primeiro traduz a perspectiva do ensino de uma filosofia crítica que incita a aprender a filosofar, o segundo um saber sistemático que estimula a aprender a filosofia. Porém, desta questáo, decorre outra: de que forma e mediante quais métodos ou instrumentos é possível aprender a filosofar ou aprender a filosofia?

Entretanto, ao se colocar as referidas questôes, é necessário antes examinar os pressupostos antropológicos e epistemológicos que fundamentam o caminho a ser escolhido. Tais como: O que é método, sobretudo no ensino de filosofia? Quem é o sujeito que aprende? Em qual contexto histórico-social e político ele está inserido? O que é e como se constrói o conhecimento, nesse caso, o filosófico? A partir do momento em que estas questôes forem explicitadas, torna-se mais fácil determinar uma metodologia eficaz e apropriada para o ensino de filosofia. 
Assim, de acordo com Mora (1982, p. 264), tem-se um método quando se segue um determinado caminho, para alcançar um certo fim, proposto de antemáo como tal. Este fim pode ser o conhecimento ou pode ser também um fim humano ou vital. Enfim, o método é um dos aspectos mais importantes relacionados às práticas pedagógicas do professor, uma vez que uma proposta de ensino bem elaborada só tem a contribuir com a aula.

Dessa forma, torna-se imprescindível que os planos de curso da disciplina de filosofia sejam bem planejados, pensados, isto é, com a finalidade específica de despertar o interesse do aluno pela temática desenvolvida. É fato que os jovens têm demonstrado certa descaso pelo conhecimento, principalmente o chamado conhecimento bancário. Em geral eles se tornam indiferentes à realidade que os cerca e todo o aparato oferecido pela escola parece-lhes sem sentido e sem utilidade; assim, os professores se veem às vezes sem recursos para trazê-los do mundo virtual ao real. Todavia, como se sabe,

a produtividade de qualquer metodologia depende, predominantemente, da capacidade profissional do professor, de seu entusiasmo, de sua capacidade de fazer com que o aluno se engaje em situaçáo de aprendizagem. Nenhuma técnica de ensino ou recurso audiovisual, por si só, garante a qualidade da aprendizagem. (VALE, 1995, p. 68-69)

Finalmente, o desinteresse do aluno está, na maioria das vezes, relacionado ao mau desempenho do professor, aulas improvisadas e sem objetivos claros. Por isso, é necessário repensar os cursos de formação do professor de filosofia para o Ensino Médio. Sabe-se que a academia, no conjunto de suas atividades, tem se preocupado mais com a consolidação de sua pós-graduação stricto sensu, com a formação de pesquisadores que possam assumir a docência no ensino superior. Enquanto isso, a licenciatura, que forma profissionais para atuarem no Ensino Médio, fica aquém do desejado. Sobre a questão vale observar um trecho de uma entrevista concedida à revista Inquietude, pelo professor Gonçalo Armijos Palácios, professor titular de Filosofia na Universidade Federal de Goiás. Questionado sobre o curso de Licenciatura na UFG, responde:

Como todos sabemos, a licenciatura, no curso de filosofia em Goiânia, foi sempre jogada às traças. E sempre encarregavam dessa área o ingênuo que chegava de fora, estrangeiro mesmo, como o Ralph e eu mesmo. 
Naturalmente, houve esforços para contornarmos essa situaçáo, mas nunca foi fácil. (MOTA; NASCENTE; RODRIGUES FILHO, 2010, p. 120)

Também o professor Sílvio Gallo discorre sobre essa questão:

Nossos cursos nunca se esforçaram, de fato, para formar professores de Filosofia para o Ensino Médio. Primeiro, porque não havia aulas; depois, porque elas eram escassas. Mas, também, porque em larga medida os departamentos de Filosofia pensavam que sua função era ensinar Filosofia; ensinar a ensinar seria a tarefa de pedagogos, dos departamentos de Educação. Penso que após a aprovação da obrigatoriedade da disciplina Filosofia, nossos cursos de Licenciatura estáo se repensando e precisam se repensar. A formação de bons professores é que poderá consolidar a Filosofia no Ensino Médio. Sem bons professores de Filosofia isso não acontecerá. E não teremos bons professores de Filosofia se não tivermos bons cursos de Licenciatura em Filosofia. Sintetizando, penso que precisamos admitir que, historicamente, nossos cursos não estiveram comprometidos com a formação de professores para a educação média e, portanto, essa formação nunca foi, efetivamente, boa. E que hoje é absolutamente necessário que nos empenhemos em levar a qualidade dos bons cursos de bacharelado em Filosofia também para a licenciatura. (ORLANDI, 2011, p. 1)

Embora, conforme Gonzalo, haja muito empenho por parte de alguns professores da academia em realizar mudanças relevantes na formação dos professores de filosofia, essas transformaçōes foram efetuadas, sobretudo, em relação ao estágio que antes consistia em ministrar apenas uma aula; o licenciando não passava pelo processo de observação da escola e dos alunos. Nesse sentido, a partir dos meados do ano de 2000, o estágio na Universidade Federal de Goiás, passou a ser ministrado em cinco etapas: estágio I, II, III, IV e V; dessa forma, o estagiário nas primeiras etapas conhece o espaço físico da escola onde pretende estagiar, toma conhecimento das normas e funcionamento da mesma e interage com professores e alunos. Este processo contribui para o embasamento teórico e prático do profissional que deseja tornar-se um filósofo professor. Ainda sobre a questão do preparo para o ensino, afirma Nielsen Neto (1986, p. 47):

[...] o ensino de filosofia, para ser eficiente, náo pode ser aleatório. Isso significa que ela só deve ser ministrada por alguém licenciado. A improvisaçáo nunca deu certo em atividade alguma, muito menos em 
filosofia. Mesmo entre os licenciados na disciplina, é possível encontrar alguns que não tiveram a oportunidade de examinar com mais vagar certos momentos da história da filosofia. Isso porque é essencial que o aluno percorra a história do pensamento para perceber que filosofia não é estado de espírito, nem, muito menos, conduta de vida. É imprescindível que o educando saiba disso e distinga o pensamento filosófico de vulgaridades que são divulgadas em seu nome.

Nessa perspectiva, não basta formar bons professores. É necessário que a Universidade e o Ministério da Educação atuem no sentido de fiscalizar e coibir a contratação de professores suplentes de filosofia.

Retomando as questões, o que ensinar em filosofia e como ensinar, é comum citar Kant em Crítica da razão pura. Segundo o autor, só é possível aprender a filosofar, aprendendo a exercitar o talento da razão. Isso porque, para Kant, a filosofia é um saber que está sempre incompleto.

Só é possível aprender a filosofar, ou seja, exercitar o talento da razão, fazendo-a seguir os seus princípios universais em certas tentativas filosóficas já existentes, mas sempre reservando à razão o direito de investigar aqueles princípios até mesmo em suas fontes, confirmando-os ou rejeitando-os. (KANT, 1983, p. 407-408)

Contrariamente a Kant, Hegel sustenta não haver diferença entre aprender filosofia e aprender a filosofar, pois somente é possível aprender a filosofar aprendendo filosofia. A filosofia se aprende e se ensina, nas palavras de Hegel (1991, p. 140), "na mesma medida em que [...] qualquer outra ciência”. Nesta lógica, o estudante deve ser submetido ao conteúdo específico da matéria e, a partir de então, deve começar a formular e efetivar sua compreensão, num processo em que o professor é o mediador da aprendizagem. Porém,

[...] o estudo da filosofia é um trabalho próprio, já é uma aprendizagem - a aprendizagem de uma ciência configurada, já existente. Esta constitui um tesouro que consta de um conteúdo adquirido, disposto, formado; este bem herdado existente deve ser adquirido pelo indivíduo, quer dizer, deve ser aprendido. O professor o possui; ele o pensa previamente, os alunos o pensam depois. (HEGEL, 1991, p. 141)

É importante ressaltar que tanto Hegel como Kant se manifestam contra a doutrinaçâo filosófica. Ambos defendem o pensar por si mesmo, 
pois o ato de filosofar é constituído de passos conscientes na análise e na crítica dos sistemas filosóficos já existentes, o que proporciona o exercício da razão. Filosofar é, portanto, atribuir à razão o direito de investigar as fontes, os princípios, aceitando-os ou não.

Dessa maneira, as dificuldades às quais o professor de filosofia está sujeito são muitas. Além do desinteresse e da falta de comprometimento dos alunos com o conhecimento em geral e, principalmente, com esta disciplina, o professor tem de provar não só para a escola, mas para os pais e, inclusive, para a sociedade de um modo geral a sua a utilidade. A existência de várias matérias na escola é naturalmente aceita; todavia, a presença da Filosofia incomoda, sobretudo aos subjugados politicos. É o que afirma Marilena Chauí: "Ninguém questiona o porquê da matemática, mas questiona o porquê da filosofia, qual a sua utilidade" (1996, p. 12). Por isso, faz-se necessário que o docente tenha claros os objetivos que pretende alcançar e reflita com seus alunos sobre isso em seu primeiro contato com eles.

O que se observa quanto às aulas de filosofia é que, se planejadas e bem ministradas, há muitos alunos que prezam a discussão e apresentam predisposição para filosofar. Enfim, aqueles que têm aulas de filosofia desde o Ensino Fundamental chegam ao Ensino Médio conscientes do quanto o filosofar foi importante para a construção de argumentos mais consistentes e, consequentemente, para seu crescimento na produção de textos.

Seguramente o filosofar, quando bem conduzido, não consistindo apenas de achismos, contribui satisfatoriamente para a autonomia e o desenvolvimento do pensamento crítico dos alunos. Kant define o pensamento crítico em Crítica da faculdade do juízo (2005, p. 61), de acordo com os seguintes princípios fundamentais: 1. Pensar por si mesmo; a garantia da autonomia do pensamento; 2. Pensar do ponto de vista do outro; significando o pensamento alargado, capaz de ultrapassar os limites do estritamente subjetivo; 3. Pensar de forma consistente; o princípio, segundo Kant, da própria razão, resultado da combinação dos dois primeiros. Kant defende de forma clara o exercício da razão, ou seja, o ato ou ação de pensar por si mesmo.

Do mesmo modo, afirma o professor de Filosofia da PUC-Rio, Danilo Marcondes (2004, p. 64):

O grande desafio para o ensino da filosofia consiste em motivar aquele que ainda não possui qualquer conhecimento do pensamento filosófico, ou sequer sabe para que serve a filosofia, a desenvolver o interesse por 
este pensamento, a compreender sua relevância e a vir a elaborar suas próprias questóes.

É com uma atitude entusiasta que o professor conquista e desperta o interesse do seu aluno. Os jovens tendem a se interessar somente por aquilo que tem utilidade imediata em suas vidas, são práticos. Sendo assim, o professor deve mostrar a eles o quanto o filosofar é útil no seu cotidiano, na construção de suas ideias; enfatizar que da filosofia nasceram as demais (disciplinas) e cada uma, de um jeito ou de outro, participa de alguma maneira da ação filosófica. A ciência estaria estagnada se os cientistas não filosofassem.

A filosofia oferece uma oportunidade única, um espaço especial para o ser humano pensar em si mesmo - esta é sua particularidade. Enquanto as demais disciplinas se preocupam em repassar conteúdos, ou seja, se empenham em cumprir um programa que é sempre muito extenso, o filosofar conduz o aluno à reflexão. É importante pensar aqui neste espaço em relação aos conteúdos. $\mathrm{O}$ docente deve estar atento a isso, porque se eles forem muito amplos no plano de curso, não haverá os momentos necessários à introspecção, à verticalização. Como é comum na matriz curricular, em apenas uma ou, em pouquíssimas escolas, duas aulas semanais, não é possível cumprir uma programação muito vasta. Assim, é preferível um plano com os temas da atualidade mais relevantes, a serem tratados com mais profundidade, a um plano extenso, mas tratado com superficialidade.

Sobre essa questão afirma Cesar Augusto Ramos em seu artigo sobre o ensino da filosofia:

O educador não deve, também, transformar o educando em mero depositário de informaçôes, pois o efeito passivo de acúmulo do conhecimento com pretensóes meramente eruditas desestimula o homem a pensar por si mesmo, além de tornar-se um saber pedante e estéril. (2007, p. 197-202)

É este também o posicionamento de Kohan:

Não nos parece interessante defender a presença da filosofia na escola a qualquer custo e de qualquer forma. Dependendo do como a filosofia está inserida, pode ser algo interessante e enriquecedor na formação de adolescentes e jovens, mas também pode ser mais um amontoado de conteúdos sem sentido que os alunos precisam assimilar. (2002, p. 22) 
Segundo as reflexões apresentadas, o que é se deve ensinar é a filosofar, estabelecendo, no entanto, uma conexão desse trabalho com a história da filosofia. Nunes e Gallo propóem que as aulas desta disciplina sejam divididas em partes. Segundo Nunes (1986), os momentos pelos quais as aulas de filosofia devem passar, são: o propedêutico, o interrogativo, o dialógico, o textual, o diversificado e o gradual.

E segundo Gallo (2007), as aulas de filosofia devem ser divididas em: sensibilização, momento em que o professor aproxima seus alunos da temática, isto é, leva-os ao reconhecimento da importância desta para a vida deles. Segundo momento: problematização dialógica - por meio do diálogo, o professor transforma a temática em um problema filosófico a ser pensado. Terceiro momento: investigação e conceituação - consistem na apresentação de conceitos que possam contribuir na possivel soluçâo da problemática. É importante observar que ambos propóem a busca das soluções apresentadas pelos filósofos ao longo da história da filosofia. Nesta busca cabe ao professor indicar aos alunos os filósofos que pensaram sobre a mesma temática.

Em síntese, são interessantes estas propostas apresentadas por Nunes e Gallo, de que os temas sejam desenvolvidos por partes, pois isso facilita a compreensão e evita que as aulas se tornem apenas uma sequência de achismos. Deve-se, então, partir da realidade dos estudantes, de seu contexto, de sua experiência de vida, de suas inquietaçóes, pois o aluno não é uma tabula rasa, traz consigo saberes e práticas. Conforme afirma Maria Irene Vale (1995, p. 70), se o ensino se torna mais próximo do real, desperta maior interesse do aluno e possibilita maior aprendizagem. O professor náo pode ignorar esta realidade, vivida e explicitada pelo aluno. Mesmo que este conhecimento apresentado por ele esteja ao nível do senso comum, ele representa o ponto inicial para o conhecimento mais elaborado, crítico e organizado. É o que em outras palavras afirma Libâneo :

Esta maneira de conceber os conteúdos do saber não estabelece oposição entre cultura erudita e cultura popular ou espontânea, mas uma relação de continuidade em que, progressivamente, se passa da experiência imediata e desorganizada ao conhecimento sistematizado. Não que a primeira apreensão da realidade seja errada, mas é necessária a ascensão a uma forma de elaboração superior, conseguida pelo próprio aluno, com a intervenção do professor.

Sugere-se, portanto, que após a sondagem sobre o que os alunos já sabem a respeito do tema, seja solicitado aos estudantes uma pesquisa 
e leitura sobre o mesmo. Em seguida, faz-se uma investigação sobre qual ou quais filósofos trataram daquele assunto, de preferência em épocas diferentes. Posteriormente, analisa-se o contexto histórico em que cada um viveu ou vive. É importante esta análise porque a ideia de muitos a respeito dos filósofos é que eles viveram ou vivem em outro mundo e só pensaram ou pensam coisas abstratas e absurdas que não servem para nada. Essa é uma forma de deixar de lado o que Paulo Freire chama de formalismos acadêmicos. A linguagem utilizada para os debates e reflexóes deve ser adequada ao nível do grupo. Segundo Paulo Freire,

[...] a comunicaçáo deve ser simples. Tudo o que se compreendeu, mesmo que seja complexo, pode ser expresso de forma simples. Mas a simplicidade nada tem a ver com a simploriedade: na simplicidade, se vai fundo nas coisas de maneira acessível, não complicada. No simplismo não apenas se fica na periferia do objeto tratado, mas, sobretudo, se toca no objeto de maneira pouco séria. (FREIRE apud GADOTTI, 1987, p. 32)

Deste modo, o aluno passa entáo a entender que os filósofos, enquanto seres sociais, pensam, vivem, problematizam a realidade do seu tempo. Após estas etapas, faz-se uma leitura interpretativa. Neste momento, os alunos dialogam com os filósofos e fazem uma reflexão acerca de como e porque defenderam ou rejeitaram tais ideias, estabelecendo debates entre si, em que cada um expóe oralmente o seu argumento. Fecha-se o tema com a produção de um texto dissertativo.

Seja ensinando filosofia (Hegel) ou a filosofar (Kant), conforme afirma Kohan, ninguém pode pensar e nem filosofar por outro:

Entendemos a prática da filosofia como uma experiência intersubjetiva do pensar. A experiência, não a técnica, está na base de um tal pensar. Quando se procura reproduzir ou generalizar uma experiência, ela se torna experimento, espelho do mesmo. Ao contrário, a filosofia, como experiência, não pode normalizar-se, uniformizar-se, estandardizar-se. Ninguém pode pensar por outro, ninguém pode filosofar por outro. (KOHAN, 2003a, p. 108)

[...] Nada mais, enfim, do que um exercício. Pensamento vivo e em ato. Nada de esquemas, classificaçôes, generalizaçôes. Filosofia em ato, experiência de interrogação, irrenunciável, sobre a própria experiência. Exercício singular que dá lugar a um pensamento singular. (KOHAN, 2003b, p. 224) 
Ensinar a filosofar é convidar a pensar, estimular o desejo que cada um traz dentro de si de conhecer, confirmando o que já dizia Aristóteles: "Todos os homens desejam por natureza saber" (1969, p. 36). Nesse processo, o professor tem uma tarefa fundamental, do contrário não há metodologia que desperte o interesse dos alunos; serão apenas meros espectadores sonolentos conforme afirma Paulo Freire: "A educação bancária mantém a "inconciliação entre educador-educando" e também sugere uma "dicotomia inexistente homens-mundo", na medida em que póe os homens como meros "espectadores e não recriadores do mundo" (FREIRE, 1983, p. 71).

\section{Consideraçóes finais}

Pelo exposto, então, o ensino de filosofia requer, além do compromisso filosófico do professor, o domínio de métodos e técnicas de ensino. Desse modo, o docente de filosofia é um pensador que deve julgar os seus métodos à luz de suas escolhas filosóficas. Vale observar a afirmação de Cerletti (2003, p. 62):

Vou afirmar que um professor de filosofia é aquele que, acima de tudo, consegue construir um espaço de problematizaçâo compartilhado com seus alunos. [...] Ensinar filosofia é antes de mais nada ensinar uma atitude em face da realidade, diante das coisas, e o professor de filosofia tem que ser, a todo momento, consequente com esta maneira de orientar o pensamento.

Neste sentido, de posse do conhecimento sistematizado, o professor pode elaborar sua metodologia própria, tendo em vista o perfil de seus alunos, o contexto em que eles estão inseridos e os objetivos que se pretende alcançar, lembrando que ninguém pode fazer isso pelo professor, ou seja, nem a direção e nem a coordenação.

É muito gratificante para o docente, quando, ao encerrar sua aula, os alunos continuam questionando e pedem para que haja troca com o professor da aula seguinte a fim de que o debate possa continuar. $\mathrm{O}$ método socrático ensina a característica fundamental do filosofar: o questionamento, o debate, a discussão, a polêmica e a argumentação. Sócrates conquistou, não só os jovens atenienses, incentivando-os a pensar através da maiêutica, como também a todos nós.

Embora tenha apresentado neste texto uma sequência de passos que possam conduzir melhor o filosofar em sala de aula, cada situação apresenta 
um desafio filosófico único. Se o filosofar é dar espaço para o pensamento do outro, devem ser esperadas circunstâncias inéditas, o que é muito estimulante. Logo, é comum ocorrer mudanças nas estratégias em função do objetivo fundamental: o filosofar. Assim, todas as atividades devem convergir para este propósito.

Por fim, as dificuldades práticas do professor de Filosofia são as mesmas de qualquer professor, especialmente a falta de interesse pela leitura por parte dos estudantes. Para não se frustrar, é imprescindível que o professor tenha senso de realidade, não idealizando a escola e nem os alunos.

\section{Referências}

ARISTÓTELES. Metafísica. Tradução de Leonel Vallandro. Porto Alegre: Globo, 1969.

CERLETTI, A. Ensino de filosofia e filosofia do ensino filosófico. In: GALLO, S.; CORNELLI, G.; DANELON, M. (Org.). Filosofia do ensino de filosofia. Petrópolis: Vozes, 2003.

CHAUÍ, M. Convite à filosofía. São Paulo: Ática, 1996.

DANELON, M. Ensino de filosofia e currículo: um olhar crítico aos parâmetros curriculares nacionais (ciências humanas e suas tecnologias e orientações curriculares para o Ensino Médio: Filosofia). Cadernos de História da Educação, Uberlândia, v. 9, n. 1, p. 109-129, jan./jun. 2010.

FREIRE, P. Pedagogia do oprimido. 12. ed. Rio de Janeiro: Paz e Terra, 1983. GADOTTI, M. Concepção dialética da educação. São Paulo: Cortez, 1987. GALLO, S.; KOHAN, W. Filosofia no ensino médio. Petrópolis: Vozes, 2000. GALLO, S. A filosofia e seu ensino: conceito e transversalidade. In: SILVEIRA, R. J. T; GOTO, R. (Org.). Filosofia no ensino médio: temas, problemas e propostas. São Paulo: Loyola, 2007.

HEGEL, F. (1809-1822) Escritos pedagógicos. México: Fondo de Cultura Econômica, 1991.

LIBÂNEO, J. C. Democratização da escola pública: a pedagogia crítico-social dos conteúdos. São Paulo: Loyola, 1986. 
KANT, I. Crítica da faculdade do juizo. Tradução de Valério Rohden e António Marques. 2. ed. Rio de Janeiro: Forense Universitária, 2005.

KANT, I. Crítica da razão pura. Tradução de Valerio Rohden e Udo Moosburger. 2. ed. São Paulo: Abril Cultural, 1983.

KOHAN, W. O. Infância: entre educação e filosofia. Belo Horizonte: Autêntica, 2003a.

KOHAN, W. O. Três liçôes de filosofia da educação. Educação e Sociedade, Campinas, v. 24, n. 82, p. 221-228, 2003 b.

KOHAN, W. O. Ensino de filosofia: perspectivas. Belo Horizonte: Autêntica, 2002.

KOHAN, W. O.; WAKSMAN, V. Perspectivas atuais do ensino de Filosofia do Brasil. In: FÁVERO, A. A.; KOHAN, W. O.; RAUBER, J. J. Um olhar sobre o ensino de filosofia. Ijuí: Ed. UNIJUÍ, 2002.

MARCONDES, D. É possível ensinar filosofia? E, se possível, como? In: KOHAN, W. (Org.). Filosofia: caminhos para seu ensino. Rio de janeiro: DP\&A, 2004.

MORA, J. F. Dicionário de filosofia. Lisboa: Publicaçóes Dom Quixote, 1982.

MOTA, A. G. R.; NASCENTE, D. M.; RODRIGUES FILHO, W. V. Entrevista com José Gonzalo Armijos Palácios. Inquietude, Goiânia, v. 1, n. 2, ago./dez. 2010. Disponível em: <http://www.inquietude.org/index. php/ revista/article/view/40/62>. Acesso em: 22 mar. 2012.

NIELSEN NETO, H. Prolegômenos à destruição do ensino no Brasil. In: (Org.). A filosofia no $2^{\circ}$ grau. São Paulo: Seaf/Sofia, 1986.

NUNES, B. Proposta para o ensino da filosofia no segundo grau. In: NIELSEN NETO, H. (Org.). O ensino da filosofia no $2^{\circ}$ grau. São Paulo: SEAF/Sofia, 1986. p. 153-162.

ORLANDI, J. Entrevista com o professor Sílvio Gallo. Seção filosofia na escola, da Anpof, 2011. Disponível em: <http://www.anpof.org.br/spip. php?article118->. Acesso em: 23 mar. 2012.

RAMOS, C. A. Aprender a filosofar ou aprender a filosofia: Kant ou Hegel? Trans/Form/Ação, São Paulo, v. 30, n. 2, p. 197-217, 2007. 
268 Polyphonía, v. 22/2, jun./dez. 2011

VALE, M. I. P. As questóes fundamentais da didática: enfoque político-social construtivista. Rio de Janeiro: Ao Livro Técnico, 1995.

Recebido em: 1 jun. 2012

Aceito em: 15 ago. 2012 